УДК: 616.314-089.23-77:004.891.3

\title{
МЕТОДИКА ОЦЕНКИ КАЧЕСТВА КАРКАСОВ ЧАСТИЧНЫХ СЪЕМНЫХ ПРОТЕЗОВ, ИЗГОТОВЛЕННЫХ С ПОМОЩЬЮ ЦИФРОВЫХ ТЕХНОЛОГИЙ
}

\author{
Вокулова Юлия Андреевна \\ к.м.н., ассистент кафедры клинической медицины \\ Нижегородский государственный \\ университет им. Н.И. Лобачевского \\ Жулев Евгений Николаевич \\ д.м.н., профессор кафедры ортопедической \\ стоматологии и ортодонтии \\ ФГБОУ ВО «ПИМУ» Минздрава России
}

\begin{abstract}
Аннотация: цель исследования в статье являлась оценка качества каркасов частичных съемных протезов (с металлическим базисом и дуговых), изготовленных с помощью цифровых технологий. В клиническом исследовании участвовали 15 пациентов (9 мужчин и 6 женщин) в возрасте от 42 до 76 лет. Виртуальное моделирование каркасов протезов проводили в модуле PartialCAD Module программного обеспечения DentalCAD 2.2 Valletta. Для изготовления полимерных заготовок каркасов частично съемных протезов использовали 3D принтер Asiga Max UV. Методика оценки качества каркасов частично съемных протезов, изготовленных с помощью цифровых технологий, заключалась в оценке определенных параметров и проведении некоторых клинических тестов. На основании полученных данных было установлено, что каркасы частичных съемных протезов (с металлическим базисом и дуговые), изготовленные с помощью цифровых технологий, с применением для создания полимерной заготовки будущего каркаса 3D принтера, обладают более высоким качеством, меньшими сроками адаптации к ним больных и общим снижением количества ошибок и осложнений.

Ключевые слова: цифровые технологии в стоматологии, 3D печать, $\mathrm{CAD} / \mathrm{CAD}$, каркас частично съемного протеза, 3D моделирование частично съемного протеза.
\end{abstract}




\title{
METHODOLOGY FOR ASSESSING THE QUALITY \\ OF REMOVABLE PARTIAL DENTURE FRAMES MANUFACTURED USING DIGITAL TECHNOLOGIES
}

\section{Vokulova Yuliya Andreevna Zhulev Evgeniy Nikolaevich}

\begin{abstract}
: the purpose of the study is to assess the quality of the frames of partial removable prostheses (with a metal base and arc) made using digital technologies. The clinical study involved 15 patients ( 9 men and 6 women) aged 42 to 76 years. Virtual modeling of prosthetic skeletons was carried out in the PartialCAD Module of the DentalCAD 2.2 Valletta software. The 3D printer Asiga Max UV was used for the manufacture of polymer blanks of partially removable prostheses frames. The methodology for assessing the quality of the frames of partially removable prostheses made with the help of digital technologies consisted in evaluating certain parameters and conducting some clinical tests. Based on the data obtained, it was found that the frames of partial removable prostheses (with a metal base and arc), made using digital technologies, with the use of a 3D printer frame to create a polymer blank for the future, have higher quality, shorter adaptation times for patients and a general reduction in the number of errors and complications.
\end{abstract}

Key words: digital technologies in dentistry, 3D printing, CAD/CAD, partially removable prosthesis frame, 3D modeling of partially removable prosthesis.

\section{Введение}

Компьютерное проектирование и автоматизированное производство привели к революционным изменениям не только во многих отраслях промышленности, но и в стоматологической практике [1, с. 194-221; 2, с. 106-112; 3, с. 8-44]. Современные цифровые технологии (CAD/CAM и 3D принтеры) позволяют в значительной степени автоматизировать процесс создания каркасов дуговых протезов. Вначале получают цифровые изображения моделей челюстей пациента, затем виртуально моделируют будущий каркас дугового протеза и изготавливают его беззольную заготовку аддитивным методом с помощью 3D принтера. [4, с. 4]. Научных публикаций, посвященных проведению оценки качества каркасов частичных съемных протезов (с металлическим базисом и дуговых), изготовленных с помощью 
цифровых технологий, крайне мало, что и является обоснованием необходимости проведения дальнейших исследований в этом направлении.

\section{Материалы и методы}

В клиническом исследовании участвовали 15 пациентов (9 мужчин и 6 женщин) в возрасте от 42 до 76 лет.

Сначала с помощью индивидуальной ложки и С - силиконового оттискного материла Speedex light body, Coltene (Швейцария) были получены функциональные оттиски и изготовлены гипсовые модели из высокопрочного гипса Fujirock (GC, Япония). Было определено центральное соотношение челюстей. Затем проводили разметку каркаса частично съемного протеза и получали цифровое изображение гипсовой модели в лабораторном сканере KaVo ARCTICA AutoScan.

В программном обеспечении DentalCAD 2.2 Valletta в модуле PartialCAD Module моделировали каркасы дуговых протезов или пластиночных с металлическим базисом (рис. 1). Далее с помощью 3D принтера Asiga Max UV получали заготовки каркасов частично съемных протезов из фотополимерного материала для беззольно выгораемых конструкций Freeprint Cast (Detax).

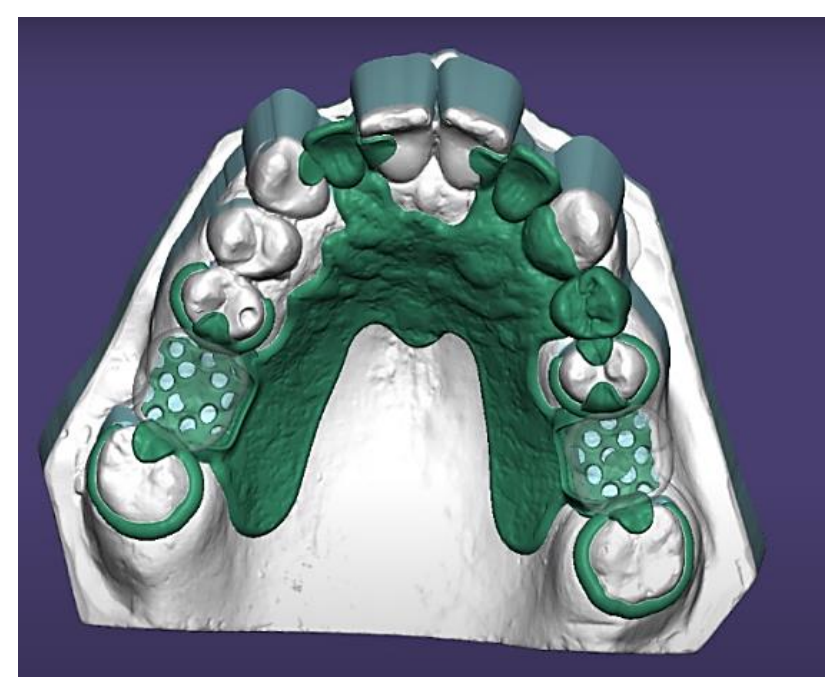

\section{Рис. 1. Цифровое изображение каркаса пластиночного протеза с металлическим базисом}

Далее осуществляли формовку заготовок каркасов протезов в кювету, выплавляли беззольный материал и прокаливали литейную форму в муфельной печи. После этого кювету помещали в литейную установку Bego Nautilus и заполняли форму расплавленным металлом. Проводили проверку каркаса 
частично съемного протеза в клинике. После этого делали постановку искусственных зубов и моделировку искусственной десны. Качество постановки зубов проверяли в клинике. Затем изготавливали пластмассовый базис и накладывали протез в полости рта пациента.

Методика оценки качества каркасов частично съемных протезов, изготовленных с помощью цифровых технологий, заключалась в оценке определенных параметров и проведении некоторых клинических тестов. Критерии оценки качества каркасов дуговых протезов представлены в таблице 1.

\section{Результаты}

Результаты оценки качества каркасов частично съемных протезов, изготовленных с помощью цифровых технологий представлены в таблице 1.

Таблица 1

\section{Критерии оценки качества частичных съемных протезов}

(с металлическим базисом и дуговых)

\begin{tabular}{|c|c|c|c|}
\hline № & Критерии оценки & Оценка & $\begin{array}{c}\text { Кол- } \\
\text { во }\end{array}$ \\
\hline \multirow[b]{2}{*}{1} & \multirow{2}{*}{$\begin{array}{c}\text { Соответствие заготовки каркаса } \\
\text { съемного протеза рисунку граннц на } \\
\text { гипсовой модели }\end{array}$} & Наличие & 15 \\
\hline & & Отсутствие & 0 \\
\hline \multirow{2}{*}{2} & \multirow{2}{*}{ Ретенция кламмеров } & Наличие & 15 \\
\hline & & Отсутствие & 0 \\
\hline \multirow{2}{*}{3} & \multirow{2}{*}{$\begin{array}{c}\text { Характер расположения опорно- } \\
\text { удержнвающнх элементов } \\
\text { (оценивается с помощью зонда) }\end{array}$} & $\begin{array}{l}\text { Окклюзнонные накладки н плечи кламмеров } \\
\text { визуально плотно прилегают к опорным зубам }\end{array}$ & 15 \\
\hline & & $\begin{array}{l}\text { Ошутимый и визуально заметный зазор, } \\
\text { клиннчески неприемлемо }\end{array}$ & 0 \\
\hline \multirow{2}{*}{4} & \multirow{2}{*}{ Оценка положения каркаса протеза } & $\begin{array}{c}\text { Между каркасом и слизистой оболочкой 1-1,5 } \\
\text { мм }\end{array}$ & 15 \\
\hline & & $\begin{array}{l}\text { Каркас оказывает давление на слизистую } \\
\text { оболочку, мешает движенню языка }\end{array}$ & 0 \\
\hline \multirow{3}{*}{5} & \multirow{3}{*}{ Наложение каркаса протеза } & $\begin{array}{c}\text { Каркас протеза } \\
\text { накладывается без усилий }\end{array}$ & 13 \\
\hline & & $\begin{array}{c}\text { Каркас протеза } \\
\text { накладывается с усилием }\end{array}$ & 2 \\
\hline & & $\begin{array}{c}\text { Каркас протеза не } \\
\text { накладывается }\end{array}$ & 0 \\
\hline \multirow{3}{*}{6} & \multirow{3}{*}{ Фиксация каркаса } & Фиксируется хорошо & 15 \\
\hline & & Не фиксируется & 0 \\
\hline & & Балансирует & 0 \\
\hline \multirow{2}{*}{7} & \multirow{2}{*}{$\begin{array}{l}\text { Необходимость коррекции каркаса } \\
\text { съемного протеза }\end{array}$} & Отсутствие & 13 \\
\hline & & Наличне & 2 \\
\hline \multirow{3}{*}{8} & \multirow{3}{*}{$\begin{array}{c}\text { Субъективные ошущения пациента } \\
\text { (опрос) }\end{array}$} & $\begin{array}{c}\text { Отсутствие дискомфортных явлений, быстрое } \\
\text { привыкание }\end{array}$ & 12 \\
\hline & & $\begin{array}{c}\text { Наличие легкого дискомфорта, ощущения } \\
\text { непривычности }\end{array}$ & 3 \\
\hline & & Непреодолимый дискомфорт & 0 \\
\hline
\end{tabular}


В ходе проведения исследования было выявлено, что в 100\% случаев заготовки каркаса съемного протеза, полученные с помощью 3D принтера Asiga Max UV, соответствовали начерченным границам каркасов на гипсовых моделях челюстей. В 100\% случаев наблюдалась хорошая ретенция кламмеров и окклюзионные накладки и плечи кламмеров визуально плотно прилегали к опорным зубам. В 100\% случаев каркасы частично съемных протезов не оказывали давление на слизистую оболочку. В 13,3\% случаев каркасы протезов накладывались с усилием, и было необходимо провести их коррекцию, на наш взгляд, это связано с возможными погрешностями, возникающими на этапе замены полимерного материала заготовки каркаса на металл в процессе литья и с усадкой сплава. В 100\% случаев после наложения каркасы частично съемных протезов фиксировались хорошо в полости рта пациентов, без балансирования. У 20\% пациентов после наложения частично съемного протеза отмечалось наличие легкого дискомфорта, ощущения непривычности, которые через несколько дней проходили.

\section{Заключение}

На основании полученных данных было установлено, что каркасы частичных съемных протезов (с металлическим базисом и дуговые), изготовленные с помощью цифровых технологий, с применением для создания полимерной заготовки будущего каркаса 3D принтера, обладают более высоким качеством, меньшими сроками адаптации к ним больных и общим снижением количества ошибок и осложнений.

\section{Список литературы}

1. Карякин Н.Н., Горбатов Р.О. 3D-печать в медицине. - М.: ГЭОТАР-Медиа: 2019. - С. 194-221.

2. Ряховский, А.Н. Цифровая стоматология. - М.: ООО «Авантис», 2010. - C. 106-112.

3. Шустова В.А., Шустов М.A. Применение 3D-технологий в ортопедической стоматологии. - СПб: СпецЛит, -2016. - С. 8-44.

4. Вокулова Ю.А. Сравнительная оценка времени изготовления каркасов дуговых протезов, созданных с помощью традиционных и цифровых технологий/ Ю.А. Вокулова, Е.Н. Жулев // Стоматология для всех -2021. - № 1. - C. 4-7. https://doi.org/10.35556/idr-2021-2(95)4-7. 